\title{
Students' and Physical Education Professionals' Knowledge About First Aid Maneuvers in Cardiopulmonary Resuscitation and Syncope: A Cross-Sectional Study
}

Patrícia Caires Maceno, Sacha Clael, Pedro Victor Nogueira de Souza, Lídia Mara Aguiar Bezerra de Melo, Glauco Falcão de Araújo Filho, and Alexandre Lima de Araújo Ribeiro

Purpose: To assess and to classify the knowledge of students and physical education professionals about first aid, specifically about cardiopulmonary resuscitation and syncope.

Methods: The sample $(n=30)$ was divided into student $(n=15)$ and professional $(n=15)$. The assessments were 1 theoretical and 2 practical tests (1 cardiopulmonary resuscitation, 1 syncope) with first aid simulations.

Results: Theoretical knowledge between students and physical education professionals is similar $(5.67 \pm 1.72$; $6.53 \pm 1.41 ; p=0.142)$. However, on practical tests, CPR $(2,68 \pm 1,82 ; 4,08 \pm 1,46 ; p=0,028)$, syncope $(4,07 \pm$ $1,96 ; 6,47 \pm 0,70 ; p<0,000)$ and total score $(12,42 \pm 3,08 ; 17,08 \pm 2,38 ; p<0,000)$ the professionals had a better performance than the students.

Conclusion: Theoretical knowledge of students and Physical Education professionals is similar; however, the professionals' practical knowledge is statistically different from students.

Keywords: CPR; Cardiopulmonary arrest; Basic Cardiac Life Support; Fainting; Resuscitation

In recent years, there has been a noticeable increase in physical activity among the population, whether for aesthetic purposes or quality of life (Cruz et al., 2018). Furthermore, during physical activity malaise, dizziness and even cardiopulmonary arrest can occur, in some cases, specialized assistance from trained rescuers is necessary. The absence of rescuer has made the gyms and sports training centers become headlines, due to incidents that occurred in these training places (Bonde, 2016; Caixeta, 2019; EF, 2012; Menezes, 2015).

First aid (FA) aims to give the victim (sick or injured) basic life support, reduce suffering, prevent worsening health, and reduce infections possibility until the arrival of specialized help (Karen et al., 2013; Kawamoto, 2002). Basic life support can be done by a person with or without specialized training. In this situation, the rescuer will be responsible for managing the situation, taking action and keeping the victim stable (Arasu et al., 2020).

Knowing that all physical education professionals must have an applied knowledge of first aid (Tojal et al., 2004), and that being recognized by the National Health Council as health professionals, they cannot fail to provide assistance (CONFEF, 2008); educational institutions have a specific first aid course with the aim to train the professionals. But will these future professionals be able to assimilate and put into practice the content taught? Therefore, it is also important to know the knowledge level of trained professionals, whether they recognize the basic symptoms for some diseases, and finally, whether they know how to 
provide first aid correctly. (Kamcheva-Panova \& Mihailova, 2019).

Therefore, the aim of this study was to assess and classify the knowledge of students and physical education professionals about first aid (FA), specifically about cardiopulmonary resuscitation (CPR) and syncope.

\section{Methods}

\section{Overview}

This study was conducted from October to November 2018. The study was constructed according to the Declaration of Helsinki and all participants signed a consent form. Also, this study follows the Strengthening the Reporting of Observational Studies in Epidemiology (STROBE) reporting guidelines for crosssectional studies.

\section{Sample}

Fifteen physical education students, at the Faculty of Physical Education of the University of Brasilia, and 15 physical education professionals, of both sexes, participated in this study.

Inclusion criteria for students: undergraduate status in the 2nd semester of 2018, and have taken the discipline of FA at least within last year. In the group of professionals, they needed a bachelor's in physical education for at least one year, be working in gyms, and actively registered with the Regional Council of Physical Education of the 7th Region (CREF7).

\section{Instruments}

Two scenarios were constructed (Supplementary material 1) for practical tests, one for syncope and one for CPR. For each scenario the participant should have to identify the case and perform the maneuvers recommended by the International Federation of Red Cross/ Red Crescent (2016) (Red Cross) and the Military Fire Department (based on the American Heart Association guidelines) until the arrival of the specialized assistance. Also, to score these evaluations a worksheet was created for the practical tests
(Supplementary material 2). In the syncope test, a living model (trained researcher with the entire memorized script) was used. In addition, for the CPR test a specialized training manikin was used. In both cases, the participant should speak out loud all findings, so that the evaluator could write down all the necessary data.

Similarly, a questionnaire with 12 true or false questions was used for the theoretical test (Supplementary material 3). The total of 12 questions, 6 were for $\mathrm{CPR}$ and 6 were for syncope. The questionnaire (theoretical test) and scenario (practice test) was constructed by authors (PCM and GFAF) based on the procedures of the Red Cross and of the Military Fire Department of the Federal District, and approved by 4 experts from Brazil's mobile emergency service (SAMU) and military firefighters (CBM)..

In addition to the assessment instruments, the classification of knowledge on FA was created according to the score obtained in the theoretical and practical tests (Table 1). This classification was approved by professionals responsible for teaching and supervision the first aid of the Brazilian Red Cross, the Military Fire Department, and the Mobile Emergency Service.

Table 1: Knowledge classification about first aid

\begin{tabular}{cc}
\hline Classification & Grade \\
\hline Insufficient & 0 to 7 \\
Regular & 8 to 15 \\
Good & 16 to 22 \\
Great & 23 to 30 \\
\hline
\end{tabular}

\section{Procedures}

Student data collection was conducted in a laboratory at the Faculty of Physical Education at the University of Brasilia. The professionals' data collection was conducted in their workplace. In both cases, the first moment of the collection was to check the inclusion criteria. After that moment, all participants were submitted to a syncope 
practical test, followed by a CPR practical test and, finally, a theoretical test. They did not receive any prior information about the maneuvers that should be performed.

On the syncope test, the living model complained about malaise, and the participant was expected to carry out an initial assessment with the aim to obtain the most information regarding the apparent victim signs (ex. pallor, hyperventilation, sweating and cold skin), beyond the information that would be provided by the researcher (pulse and heart rate) if questioned or the participant checked. After the initial assessment, the participant should place the living model in the Trendelenburg position. After completing this stage, the living model was replaced by a mannequin, so that the CPR test could be performed. The participant should identify the case and immediately start resuscitation maneuvers, which consists of checking vital signs provided by the researcher once the participant checks, and then providing insufflation every 5 seconds for 1 minute. After the second complete cycle ( 2 minutes) the researcher reported that the victim was in cardiopulmonary arrest. At this point, the participant should start a maneuver of 30 compressions for 2 insufflations in 15 seconds or 220 to 240 compressions in 2 minutes. It is important to note that every assessment was timed and that checking of vital signs would only be provided if the participant asked, otherwise the participant would not be informed.

\section{Statistical Analysis}

Normality was checked using the Shapiro-Wilk test. For comparison between groups, the independent t-test was used on the theoretical test data, CPR test, a total of practical tests and on the total of tests (theoretical + practical). For the practical test, syncope data, the Mann-Whitney test was used. We adopted $\mathrm{p} \leq 0.05$ as the level of statistical significance.

\section{Results}

Table 2 show that there was no difference between students and professionals on theoretical assessment. However, all results of practical assessments show statistically significant differences between professionals and students. Finally, the difference in practical assessments influenced the difference in the final classification for professionals and students. Therefore, they are classified as good for professionals and regular for students.

\section{Discussion}

Since the basic knowledge about FA is mandatory in a Physical Education program, including with a

Table 2: Students and professionals' knowledge about first aid.

\begin{tabular}{|c|c|c|c|c|c|}
\hline \multirow{2}{*}{ Test } & \multicolumn{2}{|c|}{ Students } & \multicolumn{2}{|c|}{ Professionals } & \multirow{2}{*}{$\rho$} \\
\hline & $(\bar{x} \pm S D)$ & Classification & $(\bar{x} \pm S D)$ & Classification & \\
\hline Theorical & $5,67 \pm 1,72$ & & $6,53 \pm 1,41$ & & 0,142 \\
\hline PTCPR & $2,68 \pm 1,82$ & & $4,08 \pm 1,46$ & & $0,028 *$ \\
\hline PTS & $4,07 \pm 1,96$ & Regular & $6,47 \pm 0,70$ & Good & $0,000^{+}$ \\
\hline TPT & $6,75 \pm 2,93$ & & $10,55 \pm 1,75$ & & $0,000 *$ \\
\hline Total & $12,42 \pm 3,08$ & & $17,08 \pm 2,38$ & & $0,000 *$ \\
\hline
\end{tabular}

$\overline{\boldsymbol{x}}$ : Mean; SD: Standard Deviation; PTCPR: Practical Test of Cardiopulmonary Resuscitation; PTS: Practical Syncope Test; TPT: Total Practical Tests; ${ }^{*}$ statistically significant difference in $\mathrm{t} \mathrm{test} ;{ }^{\dagger}$ statistically significant difference in Mann-Whitney test. 
specific discipline to deal with the subject, the result found in the theoretical test was expected, that professionals in the market for at least 1 year, would have greater knowledge than students. Similar results were found in other studies (Aly \& Ahmed, 1993; Halawani et al., 2019). Also, as these professionals do not work in the specialized assistance (e.g. emergency medical services, the Red Cross or the Military Fire Department), it was expected that they would not have full knowledge of the subject, that is, that did not reach a maximum score.

Despite not knowing how to do FA, many people (including non-health professionals) have a minimal knowledge about the FA practice. However, health professionals, even if they do not work with specialized assistance, must know how to perform basic support life maneuvers to maintain the life of any person until the proper assistance arrives at the place. However, the results show us that the students, even having already undergone the mandatory basic training course, did not reach a grade similar to the professionals. The data suggests that some factors beyond knowledge may be associated with knowing how to do FA. Thus, the fact that as students may not yet have been exposed to a real FA situation, whether in their class or not, they end up neglecting the importance of this topic. By contrast, as the professionals are the ones in charge of a weight room, gym, swimming pool and other places and activities inherent to the profession, they probably already had to perform some assistance or simply they have long time experience (Ganfure et al., 2018). Also, the American Heart Association updates the FA protocol guidelines every 5 years, and some institutions charge that their employees undergo such an update.

Thus, the difference in results found in practical assessments between students and professionals was also expected. However, it is interesting to note that this difference did not fully meet our expectations. Many professionals have lost marks on basic questions such as checking vital signs and the correct location to perform the cardiorespiratory massage.

Given the results along with the necessary knowledge to perform FA in case of cardiopulmonary arrest or syncope, we propose to classify the level of knowledge on this course. Such classification returns to us that Physical Education students have regular knowledge. This result is similar to that found in other studies (Ganfure et al., 2018; Halawani et al., 2019; Pei et al., 2019).

The level of professionals' knowledge is also in line with expectations. However, since the professionals reached a low score in the good classification, and the standard deviation exceeds the limit of the classification down, leaving some professionals in the regular classification, it is important to note the significant gaps of knowledge about FA these participants. So, they should be required to participate in an interactive training of FA maneuvers, on a regular basis (Bakalarski, 2020, Wiśniewski \& Majewski, 2007).

\section{Limitations}

The limitations of the study are a small sample size, the use of only one University, and not having selected professionals graduated at the same institution as the students.

\section{Conclusion}

Theoretical knowledge of students and Physical Education professionals is similar; however, the professionals' practical knowledge is statistically different from students.

\section{Acknowledgements \& Funding}

We thank the First Aid instructor of the National Commercial Learning Service of the Federal District (Senac-DF), Mr. Lewisson Crisóstomo Pereira, for encouraging and collaborating with the conception of this work. 


\section{Conflict of Interests}

We acknowledge one author who served as the FA instructor may represent an intellectual conflict of interest to readers.

\section{Corresponding Author}

Professor Alexandre Ribeiro, alexandrelaribeiro@gmail.com

\section{Section Editor}

Dan Anton

\section{References}

Aly, S. A., \& Ahmed, N. I. (1993). Assessment of physical education faculty students' knowledge about first aid. The Journal of the Egyptian Public Health Association, 68(1-2), 101-118.

Arasu, S., Mathew, S. S., Ramesh, N., Fathima, F. N., \& Johnson, A. R. (2020). Safety First: Awareness and attitude regarding first aid among college students - A Cross-sectional study in Urban Bangalore. International Journal of Health \& Allied Sciences, 9(1), 25-28. https://doi.org/10.4103/ijhas.IJHAS_100_19

Bakalarski, P. (2020). Assessment of teachers' knowledge about first aid. Critical Care Innovations, 3(1), 1823. https://doi.org/10.32114/CCI.2020.3.1.18.23

Bonde. (2016). Morte súbita de atletas e em academias; como acontece e de que forma pode ser evitada. Bonde. https://www.bonde.com.br/saude/corpo-e-mente/morte-subita-de-atletas-e-em-academiascomo-acontece-e-de-que-forma-pode-ser-evitada-427422.html

Caixeta, F. (2019). Judoca do DF sofre parada cardíaca e morre após meia hora de treino. Metrópoles. https://www.metropoles.com/distrito-federal/judoca-do-df-sofre-parada-cardiaca-e-morre-apos-meiahora-de-treino

CONFEF. (2008). Socorros de Urgência em Atividades Físicas. Revista Educação Física, 28(junho), 14-15.

Cruz, M. S. da, Bernal, R. T. I., \& Claro, R. M. (2018). Trends in leisure-time physical activity in Brazilian adults (2006-2016). Cadernos de Saúde Pública, 34(10), 1-14. https://doi.org/10.1590/0102-311x00114817

EF, P. (2012). Primeiros socorros: sua academia está preparada? Portal Da Educação Física. https://www.educacaofisica.com.br/fitness2/gestao-academias/primeiros-socorros-sua-academiaesta-preparada/

Ganfure, G., Ameya, G., Tamirat, A., Lencha, B., \& Bikila, D. (2018). First aid knowledge, attitude, practice, and associated factors among kindergarten teachers of Lideta sub-city Addis Ababa, Ethiopia. PLOS ONE, 13(3), e0194263. https://doi.org/10.1371/journal.pone.0194263

Halawani, L. M., Alghamdy, S. D., Alwazae, M. M., \& Alkhayal, W. A. (2019). Knowledge and attitude of Saudi female university students about first aid skills. Journal of Family \& Community Medicine, 26(2), 103107. https://doi.org/10.4103/jfcm.JFCM_92_18 
International Federation of Red Cross Red Crescent Societies. (2016). International first aid and resuscitation guidelines 2016. International Federation of Red Cross Red Crescent Socieites.

http://www.ifrc.org/Global/Publications/Health/First-Aid-2016-Guidelines EN.pdf

Kamcheva-Panova, L., \& Mihailova, G. K. (2019). Injures for which first aid is needed in the school: can the teachers make the first aid? Knowledge International Journal, 30(2), 389-396.

Karen, K. J., Hafen, B. Q., Limmer, D., \& Mistovich, J. J. (2013). Primeiros Socorros para estudantes (10a). Manole.

Kawamoto, E. E. (2002). Acidentes: como socorrer e prevenir (1a). Pedagógica Universitária.

Menezes, E. (2015). Jovem de 15 anos tem ataque cardíaco e morre em academia no Prado, em BH. R7. https://noticias.r7.com/minas-gerais/jovem-de-15-anos-tem-ataque-cardiaco-e-morre-em-academiano-prado-em-bh-11032015

Pei, L., Liang, F., Sun, S., Wang, H., \& Dou, H. (2019). Nursing students' knowledge, willingness, and attitudes toward the first aid behavior as bystanders in traffic accident trauma: A cross-sectional survey. International Journal of Nursing Sciences, 6(1), 65-69. https://doi.org/10.1016/j.ijnss.2018.11.003

Tojal, J. B., DaCosta, L. P., \& Beresford, H. (2004). Ética profissional na Educação Física (1st ed.). Shape.

Wiśniewski, J., \& Majewski, W. D. (2007). Assessment of knowledge about first aid among the teachers of chosen high schools in the Western Pomerania region. Annales Academiae Medicae Stetinensis, 53(2), 114-123. http://www.ncbi.nlm.nih.gov/pubmed/18557385 